\title{
ESTADO E SERVIÇOS PÚBLICOS DE SAÚDE: UMA ANÁLISE DO DEBATE SOBRE AS ORGANIZAÇÕES SOCIAIS NO SUPREMO TRIBUNAL FEDERAL
}

\author{
Felipe Asensi ${ }^{1}$
}

Glaucia Maria de Araújo Ribeiro²

\section{Resumo}

Desde a década de 90, observa-se um movimento de privatização ao considerar atividades exclusivamente exploradas pelo Estado aquelas necessárias aos imperativos da segurança nacional. A Constituição Federal de 1988 (arts. 197 e 198, III) estimula a colaboração social no campo da saúde, de modo a atrair a sociedade civil para desempenhar atividades de interesse público. Exemplo típico é a Lei n. 9.637/1998 (regulamenta as Organizações Sociais), apesar de ser controverso o seu caráter societário e cidadão. Em Abril/2015 (ADI 1923 $\mathrm{MC} / \mathrm{DF}$ ), o Supremo Tribunal Federal (STF) pronunciou-se pela constitucionalidade das organizações sociais. Reconheceu a constitucionalidade das organizações sociais. Neste artigo, será analisado o debate a respeito da terceirização da saúde, especialmente a partir do julgamento do STF sobre as organizações sociais. Neste sentido, são analisados os principais argumentos dos ministros e as consequências para o SUS da utilização das organizações sociais.

Palavras-Chaves: Estado, Direito à saúde, Sistema de saúde, Serviços públicos, Organizações sociais

\section{INTRODUÇÃO}

A Constituição Federal de 1988 (arts. 197 e 198, III) permitiu que a iniciativa privada pudesse oferecer ações e serviços de saúde, o que pode contribuir para a articulação entre o Poder Público e os atores sociais no campo da saúde.

1 Professor Adjunto da Universidade do Estado do Rio de Janeiro (UERJ), da Universidade Santa Úrsula (USU) e da Universidade Católica de Petrópolis (UCP). Pós-Doutor em Direito pela Universidade do Estado do Rio de Janeiro (UERJ). Aperfeiçoamento em Direitos Fundamentais pela Universidad Complutense de Madrid (UCM), em Empreendedorismo pela University of Maryland (UM) e em Coaching pela University of Cambridge (UCA). Foi Visiting Scholar da Universidade de Coimbra (UC). Diretor do Grupo Brazil Thinking (Instituto Diálogo, Editora Ágora21, Games Acadêmicos, BT Consultoria). Email: felipedml@yahoo.com.br

2 Professora Assistente "C" de Direito Administrativo da Universidade do Estado do Amazonas. Atuou como Diretora eleita da Escola Superior de Ciências Sociais ESO/UEA, biênio 2013/2014. Mestre em Direito Ambiental pela Universidade do Estado do Amazonas (2004). Especialista em Administração Pública com ênfase em Direito Público. Pesquisadora do Projeto DCR/FAPEAM/CNPQ.E-mail: professoraueaglaucia@gmail.com 
Porém, é possível afirmar que, quando da criação do Sistema Único de Saúde (SUS), o objetivo consistiu em evitar a atenção à saúde regulada e controlada pelo mercado, dando-lhe o papel de coordenação e unificação visando uma adequada governança entre os entes federativos autônomos. Tanto é assim que o ordenamento constitucional vigente adotou um modelo do planejamento democrático como fundamento racionalizador para o exercício da função administrativa de fomento público, buscando atrair a sociedade civil para desempenhar atividades de interesse público sem, contudo, impor a obrigação de aderir os resistentes.

Nesta perspectiva constitucional, surgiu o mecanismo de cogestão e de gestão participativa na prestação de serviços de saúde. Destaca-se, por exemplo a Lei n. 8142/1990, que regulou a atuação dos Conselhos e Conferências de Saúde. Além disso, também foram criados modelos organizacionais na década de 90 baseados na articulação entre secretarias estaduais, municipais, redes e programas do Ministério da Saúde, Organizações Sociais (OS), Organizações da Sociedade Civil de Interesse Público (OSCIP), entre outros.

Essas chamadas "parcerias administrativas" entre o Poder Público e a sociedade civil pode evidenciar o desafio da compatibilização entre a densidade da máquina administrativa e a dificuldade de estabelecer formas eficientes e bem planejadas de atuação do Estado na efetivação de direitos. No caso da saúde, as competências do Sistema Único de Saúde (SUS) nos três níveis da federação são múltiplas, tais como: atenção básica, vigilância à saúde, urgência e emergência, atenção hospitalar e especializada, etc.

No caso das Organizações Sociais (OS), a Lei n. 9637/1998 estabeleceu a criação deste modelo e evidenciou as suas características jurídico-institucionais. Pela referida lei, as organizações sociais são pessoas jurídicas de direito privado, sem fins lucrativos, cujas atividades sejam dirigidas ao ensino, à pesquisa científica, ao desenvolvimento tecnológico, à proteção e preservação do meio ambiente, à cultura e à saúde.

Desde a sua criação, as organizações sociais têm enfrentado diversas críticas que versam sobre a sua constitucionalidade, sobre o caráter político e não social da sua constituição e também sobre a sua adequação às políticas públicas de saúde. Não obstante, as organizações sociais ainda foram submetidas à apreciação do Supremo Tribunal Federal (STF) para que se pudesse apreciar a sua constitucionalidade no Brasil.

Mais precisamente, o STF, em sede de ação direta de inconstitucionalidade (ADI 1923 MC/DF), decidiu em abril de 2015 pela constitucionalidade de alguns dispositivos legais atinentes às Leis n. 9.637/98 e 8.666/93 que cuidam, respectivamente, de Organizações Sociais (OS) e de licitações (art. 37, XXI da CRFB/88).

Neste sentido, este artigo analisa o debate sobre as OS no STF, tendo como foco a sua adequação e constitucionalidade para e efetivação do direito à saúde. Vale dizer que o artigo não levanta questionamentos acerca da possibilidade jurídica de parcerias promovidas pelos entes federativos responsáveis pelo Sistema Único de Saúde (SUS) com o particular. Diante da relevância jurídica e institucional do tema, faz-se a descrição dos 
pontos julgados pelo STF nos votos dos Ministros, tendo como foco o debate sobre a tendência de despolitização da saúde, de gerenciamento privado de interesses públicos, de prestígio às entidades intermediárias, de estímulo à descentralização social e de autorregulação setorial.

O próximo capítulo apresenta algumas características jurídicas da saúde como direito à luz da Constituição de 1988. Em seguida, serão abordados os aspectos institucionais e políticos da participação do chamado "terceiro setor" na gestão pública. Após, serão analisados os argumentos principais presentes no julgamento do STF. Por fim, a título de considerações finais, serão evidenciados os principais impasses e desafios da parceria entre Estado e sociedade para a efetivação do direito à saúde no Brasil.

\section{CONSTITUIÇÃO DE 1988 E A UNIVERSALIDADE DO DIREITO A SAÚDE}

Com a redemocratização do Brasil na década de 80 e a posse de José Sarney na Presidência da República, foram implantadas as primeiras ações integradas de saúde. Isto teve como consequência, dentre outras, a pulverização dos órgãos da saúde, o que caracterizou a desorganização das políticas públicas, a ausência de definição de metas organizacionais e desafios na política de desenvolvimento tecnológico e produção de insumos e equipamentos.

Entre os dias 17 a 21 de março de 1986, foi realizada a 8a Conferência Nacional de Saúde, considerada o marco histórico-conceitual do sistema de saúde brasileiro por estabelecer os princípios básicos que seriam consagrados na Constituição da República Federativa do Brasil de 1988 (CRFB). Os debates vencedores desta Conferência consolidaram a ideia de que a saúde deveria ser universalizada no Brasil, e isto seria feito através do aprofundamento da reforma sanitária e com a participação da sociedade civil nos processos de formação das políticas de saúde.

Ao longo da Assembleia Nacional Constituinte - especialmente durante a 7a Reunião da Subcomissão de Saúde, Seguridade e do Meio Ambiente, realizada em 22 de abril de 1987 -, os relatos diagnosticados destacavam a precariedade da saúde brasileira. A tônica das falas buscou evidenciar um sistema de saúde precário, desorganizado e excludente. Gastava-se pouco com a saúde, observando-se dificuldades até mesmo no controle de doenças endêmicas ou passíveis de prevenção por vacinas, tal como a poliomielite, a paralisia infantil, etc. Com o fortalecimento do movimento de reforma sanitária, as bandeiras pela mudança das políticas de saúde ganharam força.

Com a CRFB, o Estado brasileiro tornou-se um dos primeiros países da América Latina a reconhecer a saúde como um direito constitucional de todos e dever do Estado, valendo-se de uma perspectiva universalizante e pública deste direito. 
Nos anos seguintes, surgiu a Lei n. 8080/1990, que regulamentou o Sistema Único de Saúde (SUS) e as bases administrativas da saúde brasileira. Trata-se de um sistema de saúde unificado administrativamente, com o objetivo de respeitar a heterogeneidade do sistema federativo e preservar a autonomia dos entes da Federação. Esta Lei ainda buscou aprofundar a municipalização da saúde através da descentralização das responsabilidades, das atribuições e dos recursos, sem prejuízo da regulamentação e financiamento do SUS pela União. Desde então, a consolidação do SUS tem passado por diversas ações de planejamento em saúde, resultante no fortalecimento da gestão municipalizada, que constitui estratégia fundamental para assegurar o acesso integral à promoção, proteção e recuperação da saúde pelos cidadãos.

\section{TERCEIRO SETOR: TITULARIDADE COMPARTILHADA ENTRE O PODER PÚBLICO E A SOCIEDADE}

No Capítulo da Ordem Social da CRFB, especialmente no art. 194, observa-se o fundamento do sistema de saúde nacional, que conjuga, sob o conceito de Seguridade Social, o conjunto de ações de iniciativa dos poderes públicos e da sociedade destinados a assegurar os direitos relativos à saúde, à previdência e à assistência social. Segundo a CRFB, são objetivos da Seguridade Social: (i) universalidade da cobertura e do atendimento; (ii) uniformidade e equivalência dos benefícios e serviços às populações urbanas e rurais; (iii) seletividade e distributividade na prestação dos benefícios e serviços; (iv) irredutibilidade do valor dos benefícios; (v) equidade na forma de participação no custeio; (vi) diversidade da base de financiamento; e (vii) caráter democrático e descentralizado da administração, mediante gestão quadripartite, com participação dos trabalhadores, dos empregadores, dos aposentados e do governo nos órgãos colegiados.

No artigo 196, observa-se a universalização da saúde com o reconhecimento de que ela é direito de todos e dever do Estado, sendo garantida mediante políticas sociais e econômicas que visem à redução do risco de doença e outros agravos e ao acesso universal e igualitário às ações e serviços para sua promoção, proteção e recuperação. No artigo 198, observa-se que as ações e serviços públicos de saúde integram uma rede regionalizada e hierarquizada e constituem um sistema único, organizado de acordo com as seguintes diretrizes: (i) descentralização, com direção única em cada esfera de governo; (ii) atendimento integral, com prioridade para as atividades preventivas, sem prejuízo dos serviços assistenciais [e]; (iii) participação da comunidade.

Vale dizer que o art. 55 do Ato das Disposições Constitucionais e Transitórias (ADCT) estipulou um percentual (no mínimo) de trinta por cento (30\%) de aplicação ao setor da saúde do orçamento da seguridade social. O objetivo era vincular parte da receita das contribuições sociais de estados e municípios, com base neste percentual, assim como ocorrera com a educação. 
As normas posteriores, especialmente a Emenda Constitucional n. 29/2000, estipularam a vinculação das receitas de estados e municípios em 12\% e 15\%, respectivamente, mas interromperam a vinculação da receita, fixando somente o seu acréscimo à variação nominal do Produto Interno Bruto (PIB).

Essa emenda, entretanto, quebrou o princípio de financiamento solidário da seguridade e dificultou acréscimos superiores à variação do PIB, transformando o que deveria ser piso em teto para o aporte de recursos federais para a saúde. Essa não é uma questão menor, pois, desde 1994, com a criação do Fundo Social de Emergência (FSE), já haviam sido subtraídos da Seguridade 20\% de sua arrecadação, que se mantiveram permanentes sob a forma de Desvinculação das Receitas da União (DRU), recursos em sua quase totalidade destinados ao pagamento dos encargos financeiros da União (GADELHA, CARVALHO e PEREIRA, 2012, p. $60)$.

A Lei Orgânica da Saúde (Lei n. 8.080/1990) confirmou os ditames constitucionais da reforma sanitária, gerada durante o movimento democrático da década de 80, mas a sua aplicação enfrenta dificuldades ao ter se deparado com a austeridade da política econômica e tributária da década de 90. A situação econômica desembocou no subfinanciamento do setor da saúde, levando o poder público a enfatizar a descentralização que, devido à ausência de investimentos de recursos financeiros, resulta na desoneração de obrigações da União e distribui o encargo do gasto com a saúde pública entre as três esferas de governo. Em outras palavras, a União reduziu a sua participação nos gastos públicos para o setor, enquanto os demais entes federativos aumentaram o aporte de recursos, destacando-se, de forma substancial, o acréscimo dos gastos municipais com a saúde. Essa descentralização no financiamento do Sistema Único de Saúde (SUS) trouxe inúmeras consequências, tais como aumento dos planos e seguros de saúde públicos e privados e o incremento da participação da sociedade civil e dos setores privado na administração da saúde.

No final da década de 90, foi publicada a Lei n. 9.637/1998, que estabeleceu a criação do modelo das OS como forma de parceria entre o Estado e a sociedade civil na prestação de diversos direitos, inclusive a saúde. Buscou-se o entrelaçamento entre os setores público e privado.

Sabe-se que a prestação de serviços públicos é dever do Estado, havendo também a possibilidade de se regular o serviço prestado pelo setor privado. A ideia é que a atuação da comunidade ou da sociedade civil sobre os serviços de saúde não pode ser dissociada da responsabilidade estatal, cujo papel é assegurar direitos e distribuição racional e justa de bens sociais essenciais entre os diversos grupos da comunidade. Vale dizer que, sob este argumento, a saúde pode ser vista como um bem não sujeito às regras mercantis por se tratar de um direito de relevância pública e dever do setor público. 
Vale dizer que um argumento comum dos gestores de saúde é que a redução das desigualdades sociais abrange a divisão de poder estatal com a sociedade e envolve a capacitação do cidadão para reivindicar suas necessidades. Segundo esta perspectiva, isto contribuiria para alterar a distribuição desigual dos serviços de saúde (as condições para a saúde) a que todos os brasileiros têm direito e almejam. A CRFB autoriza que os serviços de saúde também sejam oferecidos pelo setor privado, sendo este regulado e supervisionado pelo poder estatal, apesar da CRFB não oferecer limites precisos de como deve ser operada a terceirização.

Essa articulação entre o público e o privado tem sido comum nos últimos anos, inclusive em grandes metrópoles brasileiras, tais como Rio de Janeiro e São Paulo. Observam-se estados e municípios que realizam contratos com Organizações Não-Governamentais e Organizações Sociais para o gerenciamento de hospitais, unidades básicas de saúde e centros de diagnósticos. Não é por acaso que, em 2010, o Ministério da Saúde exarou a Portaria MS/GM n. 1.034/2010, que dispõe sobre a participação complementar das instituições privadas com ou sem fins lucrativos de assistência à saúde no âmbito do SUS.

Segundo o Tribunal de Contas da União (TCU), em seu Relatório Sistêmico de Fiscalização - Saúde (Brasília 2014), "há necessidade de mudar a forma de atuação da administração pública, que deixa o papel de principal executora para se concentrar nas funções de planejamento, desenho da política, regulação, controle e avaliação" (TCU, 2014, p. 170). Tal argumentação está também presente no Acórdão n. 3.239/2013TCU/Plenário, conforme se observa abaixo:

A terceirização de ações e serviços públicos de saúde é uma medida amplamente adotada pelos entes estaduais e municipais. Cada vez mais, hospitais públicos, unidades básicas de saúde, centrais de diagnóstico, equipes da Saúde da Família, entre outros serviços, têm seu gerenciamento transferido para entidades privadas qualificadas como Organizações Sociais e Organizações da Sociedade Civil de Interesse Público ou mediante Parcerias Público-Privadas. Isso não significa que o País caminha rumo ao Estado Mínimo ou que os agentes privados irão substituir as instituições públicas. O Estado continua sendo responsável pela garantia da prestação de tais serviços, sempre visando que os cidadãos tenham seus direitos atendidos com qualidade e eficiência (TCU, 2013)

Desde a promulgação da Lei das Organizações Sociais, em 1998, têm sido utilizadas diversas estratégias de articulação entre o Estado, o SUS e o setor privado. Paralelamente, surgiram setores alinhados com os ideais da reforma sanitária que foram contra às iniciativas de terceirização da saúde, sob o argumento de que isso significaria a sua mercantilização.

O debate sobre a constitucionalidade das OS foi levado ao STF pelos Partido dos Trabalhadores (PT) e Partido Democrático Trabalhista (PDT), além de também contar com o apoio da Sociedade Brasileira para o Progresso da Ciência, da Academia Brasileira de Ciências, e do Sindicato dos Trabalhadores e Servidores em Serviços de Saúde públicos conveniados, contratados e/ou consorciados ao Sistema Único de Saúde e vol.08, nº. 03, Rio de Janeiro, 2015.pp. 1646-1662 
Previdência do Estado do Paraná.

O argumento central é que as OS estariam se substituindo ao Estado na prestação de serviço público quando se permite a cessão de recursos, servidores e bens públicos à iniciativa privada. Isto configuraria fraude à CRFB por adentrar no regime da atividade a ser prestada, que seria de natureza estritamente pública. Ou seja, segundo o Ministro Luiz Fux, se "exercida pelo Poder Público, a natureza seria de serviço público, submetida, portanto, ao regime de direito público; quando prestada pelo particular, tal atividade seria atividade econômica em sentido estrito, prestada sob regime de direito privado" (FUX, 2015).

No próximo capítulo, serão analisados os principais argumentos do julgamento sobre a constitucionalidade das OS no STF.

\section{O JULGAMENTO DO SUPREMO TRIBUNAL FEDERAL (STF) SOBRE AS ORGANIZAÇÕES SOCIAIS (OS) EM SAÚDE}

O Ministro Relator Ayres Britto da ADI 1923 MC/DF, em 31 de março de 201 1, realizou interpretação conforme a Constituição às normas que dispensam licitação em celebração de contratos de gestão firmados entre o Poder Público e as OS para a prestação de serviços públicos de ensino, pesquisa científica, desenvolvimento tecnológico, proteção e preservação ao meio ambiente, cultura e saúde.

Porém, o Ministro Luiz Fux pediu vista do processo. Em seu voto vista, o Ministro Luiz Fux expressou que a CRFB, em diversos dispositivos da saúde, afirma ser dever do Estado e da sociedade e que tal atividade é livre à iniciativa privada. A iniciativa privada estaria inserida na teoria do direito administrativo contemporâneo como um serviço público social, cujo regime jurídico desta atividade se enquadraria na ideia de serviço público compartido (ARAGÃO, 2007), serviço público não privativo (GRAU, 2005; MELLO, 2007), ou serviço público não exclusivo (DI PIETRO, 2006). Neste sentido, segundo o Ministro Fux, "o poder público e iniciativa privada podem, simultaneamente, exercê-las por direito próprio, porquanto de titularidade de ambos” (FUX, 2015). Além disso, "o particular pode exercer tais atividades independentemente de qualquer ato negocial de delegação pelo Poder Público, de que seriam exemplos os instrumentos da concessão e da permissão, mencionados no art. 175, caput, da CF” (Idem).

A decisão foi em abril de 2015 e se configura como um "divisor de águas" para a atuação das OS e para as parcerias entre o Estado e a sociedade civil nas atividades atinentes à saúde. Portanto, é fundamental destacar os pontos principais oriundos do julgamento do STF que podem influenciar esta nova configuração entre o Estado e a iniciativa privada, que certamente terá repercussões para as políticas de saúde. Abaixo estão descritos os principais argumentos: 
1. As OS atuam por direito próprio e não impulsionadas pela celebração de um contrato de gestão ou por qualquer espécie de delegação. A Lei das Organizações Sociais não delega serviços públicos, passando assim ao largo da regência do art. 175 da CRFB. Na verdade, a Lei cria um sistema de fomento e incremento às citadas atividades para que sejam realizadas com eficiência por particulares, através da colaboração público-privada instrumentalizada no contrato de gestão e com foco na terceirização da saúde;

2. A Lei das Organizações Sociais não representa a consagração do Estado Mínimo. O Estado não se ausenta de seus deveres constitucionais, apenas sua intervenção no domínio econômico e social pode ocorrer de forma direta ou indireta. Como característica de intervenção indireta, surge a presença das atividades desempenhadas por particulares, haja vista o Estado utilizar seu arcabouço legal para incentivar os próprios particulares a executem atividades de interesses públicos. Esta execução é de acordo com os princípios e diretrizes do SUS e pode o Estado atuar através da regulação, com coercitividade e fazendo uso de incentivos administrativos;

3. A atuação direta e indireta do Poder Público seja por regulação, indução ou através do fomento público (art. 174, caput, da CRFB) demonstra a densificação do aparelho estrutural administrativo. A título de ilustração dessa tendência estão os programas de privatização e de desestatização (década de 90), traduzida na relevância atribuída pela legislação às denominadas agências reguladoras, cujo modelo institucional a Corte Suprema chancelou consoante o julgamento das ADIn's n. 1.668/DF, Rel. Min. Marco Aurélio, e 1.949-MC/RS, Rel. Min. Sepúlveda Pertence;

4. A CRFB não impõe que o Poder Público atue no campo da saúde de maneira exclusiva e direta, conforme se observa no art. 199. O que se detecta no mundo jurídico atual, relata Ministro Luiz Fux, é a cobrança de controle, resultados, metas a cumprir, em respeito aos princípios da economicidade e eficiência, conforme também salienta (MOREIRA NETO, 2007). Daí as Leis das Organizações Sociais (Lei n. 9.637/98) e das Organizações da Sociedade Civil de Interesse Público (Lei n. 9.790/99) serem consideradas constitucionais pelo foco do fomento público para o atingimento de determinados deveres estatais, segundo o STF;

5. Segundo Motta, "através do fomento, o Estado busca proporcionar aos indivíduos os instrumentos do desenvolvimento econômico e do progresso sociocultural, adotando medidas capazes de incentivar a iniciativa privada de interesse coletivo nesses campos" (MOTTA, 2007, p. 210). Esta ideia, segundo o Supremo Tribunal Federal (STF), estaria baseada na efetivação do princípio da consensualidade e da participação no Direito Administrativo. Segundo Mendonça, "o fomento seria um instrumento de apoio 
ao desenvolvimento privado em direções social e constitucionalmente desejáveis" (MENDONÇA, 2010, p. 116);

6. Na Lei das Organizações Sociais, o fomento reflete a cessão de recursos, bens e pessoal da Administração Pública para as entidades privadas após a celebração de contrato de gestão. Segundo o STF, este contrato de gestão é mecanismo consensual de regulação entre Administração Pública e particular, tendo por base o princípio da consensualidade e participação dos administrados. Para o privado observar o interesse público, deve alcançar metas e resultados, o que atenua o princípio da livre iniciativa pela possibilidade de regulação estatal e evita o sucateamento do terceiro setor, haja vista a regulação do Poder Público;

7. O legislador partiu do pressuposto de que a atuação privada pode ser mais eficiente que a pública sem que o Poder Público tenha abdicado de seus deveres constitucionais de atuação na área da saúde, mas apenas pôs em prática a possibilidade válida de intervir de forma indireta para o cumprimento de tais deveres, através do fomento e da regulação. Isto ficaria condicionado, invariavelmente, a que a Administração Pública seja regulada sob o âmbito do cumprimento de metas e resultados;

8. O objetivo legal é o Poder Público buscar parcerias com o particular sem a necessidade de o Estado criar entidades públicas para a atuação direta, restando-lhe a escolha pela busca dos mesmos fins através da indução e do fomento de atores privados, caracterizando o marco legal das OS por não configurar infringência à Constituição;

9. A Lei das Organizações Sociais também não violaria o art. 37, XXI da CRFB, ou seja, o dever de licitar. O contrato de gestão não é um contrato administrativo, pois falta-lhe a característica comutativa, posto que dar-se-á por conjugação de interesses e estes se confluem em uma mesma direção. No contrato administrativo, a relação entre o Estado e o particular traduz-se na característica de partícipes, e não de interessados. Em outras palavras, o contrato de gestão tem natureza jurídica de convênio. Segundo o STF, isto afastaria a obrigação de promover a licitação a partir da figura jurídica do credenciamento. Preenchidos os requisitos legais contidos no edital de chamada pública, a entidade particular poderá, dentro da esfera de discricionariedade, oportunidade e conveniência da autoridade legal, acreditar-se como uma OS. Segundo o STF, a competência discricionária afasta a arbitrariedade, uma vez que o administrador público deve decidir pautando sua indicação nos princípios da impessoalidade, moralidade, publicidade e eficiência (CRFB, art. 37, caput). Em suma, o fato de o art. 20, II, da Lei n. 9.637/98 condicionar à discricionariedade do poder Executivo o deferimento da qualificação não conduziria à violação da Constituição; 
10. A Lei das Organizações Sociais prevê o repasse de bens, recursos e servidores públicos. Assim fica vedado dispensar a licitação baseada na possibilidade de escolha livre, desmotivada e sem prévia publicidade, o que violaria os princípios do Estado de Direito. Se o Estado possui critérios objetivos de discriminação para, excluindo todas as demais entidades da sociedade civil sem fins lucrativos, celebrar contrato de gestão apenas com as OS. Isto porque estas passaram pelo respectivo processo de qualificação (art. 24, XXIV, da Lei n. 8.666/93);

11. O mesmo raciocínio valeria para a Lei n. 9.790/99, que disciplina as Organizações da Sociedade Civil de Interesse Público (OSCIP). Embora não haja obrigatoriedade de promoção de licitação, a celebração do contrato de gestão/termo de parceria com as OS/OSCIP deve ser conduzida de maneira pública, impessoal e por critérios objetivos, como consequência da incidência direta dos princípios constitucionais que regem a Administração Pública;

12. Se as OS receberem recursos públicos, bens públicos e servidores públicos há de fazer com que seu regime jurídico seja minimamente informado pela incidência do núcleo essencial dos princípios da Administração Pública (CRFB, art. 37, caput), dentre os quais se destaca a impessoalidade. Essa incidência dos princípios administrativos deve ser compatibilizada com as características mais flexíveis do setor privado, que constituem justamente a finalidade por detrás de todo o marco regulatório do Terceiro Setor, porquanto fiado na premissa de que determinadas atividades podem ser mais eficientemente desempenhadas sob as vestes do regime de direito privado. Ou seja, segundo o STF, embora não façam formalmente licitação, tais entidades devem editar um regulamento próprio para contratações, fixando regras objetivas e impessoais para o dispêndio de recursos públicos.

13. Os trabalhadores das OS não são servidores públicos, mas sim empregados privados. Sua remuneração não deve ter base em lei, mas nos contratos de trabalho firmados consensualmente. Também não se submetem ao rigor de concurso público, mas a um procedimento de seleção de pessoal, regido por um regulamento próprio contendo plano de cargos dos empregados, obedecendo a mesma forma como a contratação de obras e serviços, sem deixar de ser posto em prática a impessoalidade e critérios objetivos. Isso é resultante do fato de que as OS não integram a Administração Pública Indireta, posto que não se enquadram nos conceitos de empresa pública, sociedade de economia mista, fundações públicas, autarquias, etc. Por serem privadas, as OS não são controladas pelo Estado, de modo que não se pode incidir a regra do art. 37, II, da CRFB;

14. Segundo o STF, também não há transgressão à CRFB no que diz respeito aos servidores públicos cedidos. A lei preserva a remuneração a que o cargo faz jus no órgão de origem. Os que tiverem direito, 
nas hipóteses restritas em que aplicáveis, às regras da paridade e da integralidade no sistema previdenciário, deverão ter como paradigma os cargos dos órgãos de origem, e não o que lhes era pago de forma transitória na organização social. E isso se impõe, ademais, porquanto não há sequer previsão para que, quanto às verbas pagas transitoriamente pelas OS, seja paga a denominada contribuição patronal $\left(\mathrm{CRFB}\right.$, art. $\left.149, \$ 1^{\circ}\right)$, o que seria indispensável para a manutenção do equilíbrio financeiro e atuarial;

15. Segundo o STF, não há qualquer inconstitucionalidade nos $₫ \$ 11^{\circ}$ e $2^{\circ}$ do art. 14 da Lei n. 9.637/98. Da leitura conjugada dos dispositivos $\$ \mathbb{S} 1^{\circ}$ e $2^{\circ}$ do art. 14 da Lei n. 9.637/98, extrai-se ser possível, em primeiro lugar, que a OS pague com recursos próprios as vantagens pecuniárias a servidores públicos que the forem cedidos. Porém, caso se trate de recursos advindos do contrato de gestão, tal pagamento apenas será válido "na hipótese de adicional relativo ao exercício de função temporária de direção e assessoria” ( $\$ 2^{\circ}$ do art. 14). Em qualquer dos casos, sob a ótica do STF, não será incorporada aos vencimentos ou à remuneração de origem do servidor cedido qualquer vantagem pecuniária que vier a ser paga pela OS. Este argumento tem relação com a natureza jurídica das OS - pertencentes ao Terceiro Setor -, o que afasta a necessidade de previsão em lei para o pagamento de verbas ainda que para os servidores cedidos. Dispõe o STF que entender de modo contrário consubstanciaria uma verdadeira "autarquização das organizações sociais", afrontando a própria lógica de eficiência e de flexibilidade que inspiraram a criação do modelo;

16. A expressão "privativo" disposta no art. $4^{\circ}$ da Lei não afasta o controle do Tribunal de Contas acerca da aplicação de recursos públicos. O termo diz respeito apenas à estrutura interna da organização social, sempre sob a égide constitucional da atuação do Tribunal de Contas (CRFB, art. 70, 71 e 74). Além disso, as OS estariam submetidas ao sancionamento por improbidade administrativa, caso façam uso irregular dos recursos públicos. A diferença, porém, está na possibilidade de poderem as entidades criadas com atendimentos aos requisitos da Lei n. 9.637/98, se habilitarem à qualificação como organização social (arts. 2º, I, f, 4º IX e X). Vale mencionar o esclarecimento de Moreira Neto: "as entidades vocacionadas ao interesse público poderiam ser constituídas sem mais formalidades que as exigidas para quaisquer outras; a diferença, porém, oferecida pela Medida Provisória, está na possibilidade de poderem as entidades criadas com atendimentos aos requisitos nela previstos, se habilitarem à qualificação como organização social” (MOREIRA NETO, 2007, p. 246).

Em suma, o STF decidiu pela constitucionalidade da prestação de serviços públicos não exclusivos por OS em parceria com o Estado. O voto do Min. Relator Carlos Ayres Britto, ADI 1923 MC/DF, procedente em 
parte, destacou a possibilidade de celebração de convênio com tais entidades, desde que conduzido de forma pública, objetiva e impessoal, em obediência aos princípios constitucionais que regem a Administração Pública (caput do artigo 37 da CFRB).

Por votação majoritária, a Corte julgou parcialmente procedente a Ação Direta de Inconstitucionalidade - ADI 1923 MC/DF, dando interpretação conforme a Constituição às normas que dispensam o procedimento licitatório para a efetivação de contratos de gestão entre o Poder Público e as OS para a prestação de serviços públicos de ensino, pesquisa científica, desenvolvimento tecnológico, proteção e preservação ao meio ambiente, cultura e saúde.

De forma sucinta e para melhor compreensão da matéria, a Tabela abaixo ilustra os principais argumentos do julgamento da ADI 1923 MC/DF, a saber: (i) cronologia; (ii) voto do Min. Relator Carlos Ayres Britto; (iii) decisão após o voto-vista do Min. Marco Aurélio; (iv) votos dos demais Ministros do STF.

Tabela 01 - Síntese do Julgamento

\begin{tabular}{|c|c|}
\hline & ADI 1923 MC/DF \\
\hline \multirow{4}{*}{ 1. Cronologia } & $\begin{array}{l}\text { As normas questionadas datam do ano de 1998, cujo o julgamento o Plenário do Supremo } \\
\text { Tribunal Federal, em julgamento iniciado em } 24 \text { de junho de } 1999 \text { e concluído em } 1^{\circ} \text { de } \\
\text { agosto de } 2007 \text { (indeferimento, por maioria, de medida cautelar requerida pelos autores, } \\
\text { em razão de descaracterização do periculum in mora). }\end{array}$ \\
\hline & $\begin{array}{l}\text { O Min. Relator Ayres Britto, em } 31 \text { de março de 2011, deu o voto pela sua procedência } \\
\text { parcial mas a ADI não foi votada pois o Ministro Luiz Fux pediu vista do processo. }\end{array}$ \\
\hline & $\begin{array}{l}\text { Após o voto-vista do Min. Luiz Fux, em } 19 \text { de maio de 2011, julgando parcialmente } \\
\text { procedente a ação, para conferir interpretação conforme a Constituiçãa, nos termos de seu } \\
\text { voto, pediu vista dos autos o Min. Marco Aurélio. }\end{array}$ \\
\hline & $\begin{array}{l}\text { Em sessão plenária de } 16 \text { de abril de } 2015 \text {, o STF decidiu pela validade da prestação de } \\
\text { serviços públicos não exclusivos por OS em parceria com o Estado. No entanto, a } \\
\text { celebração de convênio com tais entidades deve ser conduzida de forma pública, objetiva e } \\
\text { impessoal, com observância dos princípios constitucionais que regem a Administração } \\
\text { Pública (caput do artigo 37). }\end{array}$ \\
\hline \multirow{2}{*}{$\begin{array}{l}\text { 2. Voto do Min. Relator Carlos } \\
\text { Ayres Britto: julgou } \\
\text { parcialmente procedente a ação } \\
\text { direta. }\end{array}$} & $\begin{array}{l}\text { O Estado é ator por excelência prestador de serviços públicos não exclusivos, consoante } \\
\text { dispõe a Constituição Federal, cuja a atuação da iniciativa privada ocorreria de modo } \\
\text { complementar, sem substituir a ação do poder público, a exemplos dos arts. 197, 199, \$S } 1^{\circ} \\
\text { e 20(saúde). }\end{array}$ \\
\hline & $\begin{array}{l}\text { Sendo assim, manifestou-se pela inconstitucionalidade dos arts. } 18 \text { a } 22 \text { da Lei n. } 9.637 / 98 \text {, } \\
\text { já que estes demandam a extinção de entidades publicas e a absorça o das atividades } \\
\text { estatais por organizaço }{ }^{2} \text { es sociais, reservando ao Estado o mero papel de indutor, } \\
\text { fiscalizador e regulador, o que seria próprio apenas as atividades econo^micas, e na o aos }\end{array}$ \\
\hline
\end{tabular}




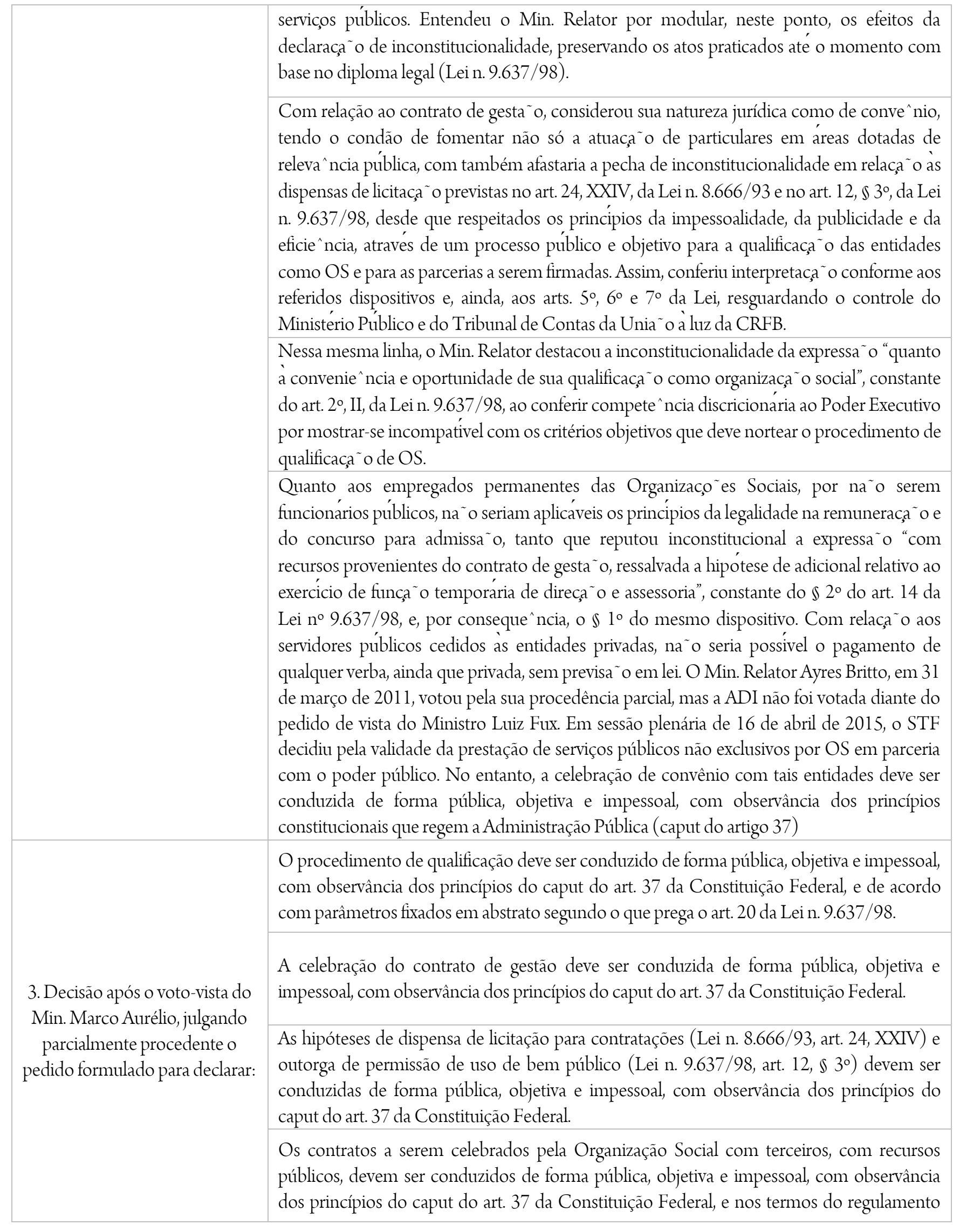




\begin{tabular}{|c|c|}
\hline & próprio a ser editado por cada entidade. \\
\hline & $\begin{array}{l}\text { A seleção de pessoal pelas OS deve ser conduzida de forma pública, objetiva e impessoal, } \\
\text { com observância dos princípios do caput do art. } 37 \text { da CRFB, e nos termos do regulamento } \\
\text { próprio a ser editado por cada entidade; e }\end{array}$ \\
\hline & $\begin{array}{l}\text { Deve-se afastar qualquer interpretação que restrinja o controle pelo Ministério Público e } \\
\text { pelo Tribunal de Contas da União da aplicação de verbas públicas, nos termos do voto do } \\
\text { Ministro Luiz Fux. }\end{array}$ \\
\hline \multirow{8}{*}{$\begin{array}{l}\text { 4. Como votaram os Senhores } \\
\text { Ministros do Supremo Tribunal } \\
\text { Federal (STF) }\end{array}$} & $\begin{array}{l}\text { Vencidos, em parte, o Min. Ayres Britto (Relator) e, julgando procedente o pedido em } \\
\text { maior extensão, os Min. Marco Aurélio e Rosa Weber. O voto do Min. Luiz Fux foi } \\
\text { acompanhado pela maioria. }\end{array}$ \\
\hline & $\begin{array}{l}\text { Não votou o Min. Roberto Barroso por suceder ao Min. Ayres Britto (aposentado no } \\
\text { decorrer do trâmite da referida ADI). }\end{array}$ \\
\hline & Impedido o Min. Dias Toffoli, o mesmo não votou. \\
\hline & $\begin{array}{l}\text { O Min. Teori Zavascki lembrou o julgamento do RE } 789874 \text {, quando o STF reforçou o } \\
\text { entendimento de que os serviços sociais autônomos possuem natureza jurídica de direito } \\
\text { privado e não estão sujeitos à regra do artigo } 37 \text {, inciso II, da Constituição. O Ministro } \\
\text { afirmou que as entidades sociais e as do Sistema S são financiados de alguma forma por } \\
\text { recursos públicos. Portanto, quando há dinheiro público envolvido, deve haver } \\
\text { necessariamente uma prestação de contas. }\end{array}$ \\
\hline & $\begin{array}{l}\text { A Ministra Cármen Lúcia considerou que o particular pode prestar os serviços em questão, } \\
\text { porém com a observação dos princípios e regras da Administração Pública para que haja } \\
\text { "ganho ao usuário do serviço público". }\end{array}$ \\
\hline & $\begin{array}{l}\text { No mesmo sentido, o Ministro Gilmar Mendes salientou a ideia de controle por tribunal de } \\
\text { contas e de fiscalização pelo Ministério Público, tendo em vista que os recursos continuam } \\
\text { sendo públicos. O Ministro afirmou que se deve buscar um novo modelo de administração } \\
\text { que possa se revelar mais eficiente do que o tradicional, mas sob os controles do Estado. }\end{array}$ \\
\hline & $\begin{array}{l}\text { O Ministro Celso de Mello observou a ineficácia do perfil burocrático da administração } \\
\text { pública e a necessidade de redefinição do papel estatal para viabilizar de políticas públicas } \\
\text { em áreas em que se mostra ausente o próprio Estado. }\end{array}$ \\
\hline & $\begin{array}{l}\text { O então Presidente do STF, Ministro Ricardo Lewandowski, salientou que as OS podem } \\
\text { colaborar com flexibilidade e agilidade na prestação de serviço público, mas estão } \\
\text { submetidas aos princípios constitucionais. Segundo o Ministro, qualquer empresa, pública } \\
\text { ou privada, e qualquer indivíduo deve prestar contas. }\end{array}$ \\
\hline
\end{tabular}




\section{CONSIDERAÇÕES FINAIS}

Desde a década de 90, observa-se um movimento de privatização ao considerar atividades exclusivamente exploradas pelo Estado aquelas necessárias aos imperativos da segurança nacional. Tanto assim que o princípio constitucional da iniciativa privada (CRFB, arts. 1. , IV, e 170, caput) permitiu a privatização de empresas públicas, ao mesmo tempo em que restabeleceu a ação estatal no domínio econômico, disposto no art. 173, caput, da Constituição.

Essa tendência constitucional fora consagrada na criação do SUS, ao estipular instrumentos de colaboração participativa no campo da saúde (arts. 197 e 198, III), proporcionando o que denominamos de fomento público. Exemplo típico desse contexto constitucional aparece na figura jurídica constante da Lei $\mathrm{n}$. 9.637/1998, que regulamenta a qualificação de entidades sem fins lucrativos como Organizações Sociais.

Em Abril/2015 (ADI 1923 MC/DF), o Supremo Tribunal Federal (STF) decidiu arregimentar debates doutrinários de grande atualidade, nitidamente identificados nas tendências de despolitização, de gerenciamento privado de interesses públicos, de prestígio às entidades intermédias, de estímulo à descentralização social e de autorregulação setorial. O motivo disso foi o julgamento pela constitucionalidade da Lei das OS, inclusive para utilização em matéria de saúde. Na análise do STF, isto atenuaria a Administração Pública de encargos secundários, cabendo ao Poder Público apenas a supervisão e o controle de atividades administrativas terceirizadas.

De fato, esta decisão não isenta a efetivação do direito à saúde de contradições e desafios. Durante este estudo, buscou-se justamente apresentá-los para oferecer um arcabouço jurídico e institucional de implementação de OS na saúde, com base no julgamento do STF. 


\title{
STATE AND HEALTH PUBLIC SERVICES: AN ANALYSIS OF THE DEBATE ON SOCIAL ORGANIZATIONS IN THE FEDERAL SUPREME COURT
}

\begin{abstract}
Since the 90s, there was a privatization movement while considering activities exclusively exploited by the state those required to the imperatives of national security. The Federal Constitution of 1988 (articles 197 and 198, III) encourages the social collaboration in the health field in order to attract civil society to perform public activities. A typical example is the Law n. 9637/1998 (regulates the social organizations), despite being controversial its citizenship and social character. In April/2015 (ADI 1923 MC / DF), the Federal Supreme Court (STF) decides about the constitutionality of social organizations. The STF recognized the constitutionality of social organizations. In this article, there will be discussed the debate about the health outsourcing, especially from the Supreme Court judgment about the social organizations. In this sense, there will be discussed the main arguments of the Justices and the consequences for the health system from the use of social organizations.
\end{abstract}

Keywords: State, Right to health, Health system, Public services, Social organizations.

\section{REFERENCIAS}

ARAGÃO, Alexandre Santos de. Direito dos serviços públicos. Rio de Janeiro: Forense, 2007

DI PIETRO, Maria Sylvia Zanella. Parcerias na administração pública. São Paulo: Atlas, 2006

GADELHA, Paulo; CARVALHO, José; PEREIRA, Telma. A saúde no Brasil em 2030: diretrizes para a prospeção estratégica do sistema de saúde brasileiro. Rio de Janeiro: Fiocruz/Ipea/Ministério da Saúde/Secretaria de Assuntos Estratégicos da Presidência da República, 2012

GRAU, Eros Roberto. A ordem econômica na Constituição de 1988. São Paulo: Malheiros, 2005

FUX, Luiz. Voto vista no julgamento da ADI 1923 MC/DF, que versa sobre a constitucionalidade das organizações sociais. Brasília: STF, 2015

MELLO, Celso Antônio Bandeira de. Curso de Direito Administrativo. São Paulo: Malheiros, 2007

MENDONÇA, José Vicente Santos de. Uma teoria do fomento público: critérios em prol de um fomento público democrático, eficiente e não paternalista. Revista de Direito da Procuradoria Geral do Estado do Rio de Janeiro, n. 65, 2010

MOREIRA NETO, Diogo de Figueiredo. Novo referencial do direito administrativo: do controle da vontade ao do resultado, In: MOREIRA NETO, Diogo de Figueiredo. Mutações do Direito Administrativo. Rio de Janeiro: Renovar, 2007

Organizações sociais de colaboração administrativa, In: MOREIRA NETO, Diogo de Figueiredo. Mutações do Direito Administrativo, Rio de Janeiro: Ed. Renovar, 2007b 
MOTTA, Carlos Pinto Coelho. Eficácia nas concessões, permissões e parcerias. Belo Horizonte: Del Rey, 2007 TRIBUNAL DE CONTAS DA UNIÃO. Acórdão n. 3.239/2013-TCU/Plenário. Brasília: TCU, 2013

Relatório técnico de fiscalização. Brasília: TCU, 2014

Trabalho enviado em 23 de junho de 2015.

Aceito em 13 de agosto de 2015. 